\title{
A GENERAL EVALUATION OF TURKEY'S ENERGY DIPLOMACY AND THE LATEST CLIMATE CHANGE STUDIES
}

\author{
Fatma Canka Kilic $^{1 *}$, Mehmet Keskin Kilic ${ }^{1}$, Muharrem Eyıdogan², Durmus Kaya ${ }^{2}$ \\ ${ }^{1 *}$ Department of Electrical and Energy, Kocaeli Vocational School, Kocaeli University, Kullar Beldesi, \\ Mahmutpaşa Cad., No: 1, P.K.: 41140, Kullar/Başiskele/Kocaeli, Turkey; \\ ${ }^{2}$ Department of Energy Systems Engineering, Faculty of Technology, Kocaeli University, 41380 Umuttepe, Kocaeli, \\ Turkey;
}

*Corresponding author Fatma Canka Kilic, e-mail: fatmacanka@ hotmail.com; Received June, 2018; Accepted July, 2018; Published January, 2019;

DOI: https://doi.org/10.31407/ijees9104

\begin{abstract}
Energy imports in Turkey increased around 36.1 percent annually for the first 10 months of 2017, and this amount rose to 41.7 percent in the August-October period, which relatively high increase in oil prices was experienced as it is expected. The country aims to reduce the dependence on imported inputs, especially in energy and related matters. Also, it is targeted to continue structural reforms with stability, accelerating technology with intensive productions and reduce the ratio of current account deficit to the national income to the level of 3.9 percent by reducing this dependence on imported energy at the end of the Medium-Term Program. In this study, a general assessment of Turkey's energy diplomacy and the latest climate change studies are examined according to up to date developments and the numbers. Therefore, it is aimed to contribute to the energy diplomacy in Turkey and raise awareness on the climate change studies.
\end{abstract}

Key words: Turkey, Energy, Energy diplomacy, Climate change studies 